\title{
Retinoic acid is both necessary for and inhibits myogenic commitment and differentiation in the chick limb
}

\author{
SUSAN REIJNTJES ${ }^{1}$, PHILIPPA FRANCIS-WEST ${ }^{2}$ and BALJINDER S. MANKOO*,1 \\ ${ }^{1}$ Randall Division of Cell and Molecular Biophysics, New Hunt's House and ${ }^{2}$ Department of Craniofacial \\ Development, Dental Institute, King's College London, Guy's Campus, London, UK
}

\begin{abstract}
Retinoic acid (RA) plays an essential role in the development of many embryonic tissues, including the developing tetrapod limb bud. At early stages of limb development, RA levels are highest proximally and regulate the migration of myoblasts into the limb. As the premyogenic progenitor cells migrate into the limb and accumulate in premuscle masses, they express Pax3 and Meox2. Myogenic differentiation is initiated by expression of Myf5 and MyoD, and both Pax 3 and Meox 2 are required for normal Myf5 expression. We show by loss of function using the inhibitor citral, that RA signalling within the limb bud is required to maintain Pax 3 and $M e o x 2$ in the progenitor and $M y f 5$ and $M y o D$ in the differentiating myoblasts. Treatment with excess RA showed a differential effect: Meox2 and Pax3 showed localised down-regulation of expression in the limb. In contrast, there was a dramatic down-regulation of expression of $M y o D$, Myf5 and Meox1. The down-regulation of myogenic gene expression in response to inhibition of RA signalling, and differential response to application of excess $R A$, in the absence of changes to cell proliferation and apoptosis, indicate that myogenic specification and differentiation in the developing limb possess a complex sensitivity to RA concentrations.
\end{abstract}

KEY WORDS: retinoic acid, myogenesis, tendon, limb bud, chick

\section{Introduction}

In the early developing vertebrate embryo, signalling molecules are required to control individual cells and to instruct them as to when and where to differentiate into their distinctive tissue types. The limb bud is an excellent model system to investigate the differentiation and patterning of muscle. The cells of the hypaxial dermomyotome of somites adjacent to the presumptive limb bud undergo an epithelial-to-mesenchymal transition in response to signals from the neighbouring lateral plate mesoderm (Chevallier et al., 1977; Christ et al., 1977; Jacob et al., 1978; Solursh et al., 1987; Hayashi \& Ozawa, 1995) and then delaminate from the somites and migrate into the limb bud. The migratory myogenic precursors initially express the transcription factor Meox2 (Mankoo et al., 1999) and CXCR4, Pax3 and Lbx1, the latter three being essential for migration (Vasyutina et al., 2005; Williams \& Ordahl, 1994; Gross et al., 2000). Pax3 is important also for specification and proliferation of limb muscle precursors (Bober et al., 1994; Goulding et al., 1994). Once the muscle progenitors reach the developing limb, they continue to proliferate and coalesce in the dorsal and ventral pre-muscle masses, and initiate differentiation by expressing the myogenic regulatory transcription factors (MRFs): Myf5, MyoD, MRF4 and Myogenin (reviewed by Pownall et al. 2002).

The Meox genes have been shown to play an overlapping and essential role in somitogenesis in the mouse (Mankoo et al., 2003). In addition to a failure of the axial skeleton to develop, compound mutant embryos (Meox $1^{-/} ; M_{\text {eo }} 2^{-/-}$) exhibit a dramatic muscle phenotype where most skeletal muscles are absent or reduced in size concomitant with reduced or absent expression of Pax3, Pax7 and Myf5 in somites (Mankoo et al., 2003). Both Meox1 and Meox2 are expressed in the developing limb buds and are conserved between chick and mouse (Reijntjes et al., 2007a), suggesting a role for both in limb muscle development. The Meox 1 expression domain overlaps that of $M y o D$, while the Meox2 domain of expression overlaps with Pax3 and not MyoD indicating a differential role of the two Meox genes (Reijntjes et al., 2007a). During mouse myogenesis, it has been demonstrated

Abbreviations used in this paper: MRF, myogenic regulatory factor; RA, retinoic acid.

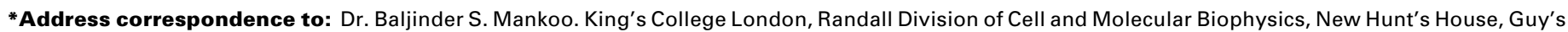
Campus, London SE1 1UL, U.K. Fax: +44-207-848-6435. e-mail: baljinder.mankoo@kcl.ac.uk 

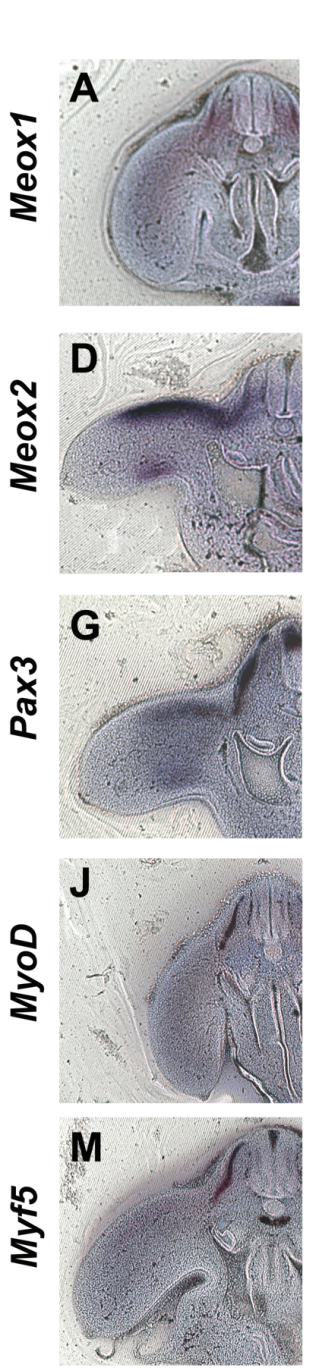

\section{Untreated}
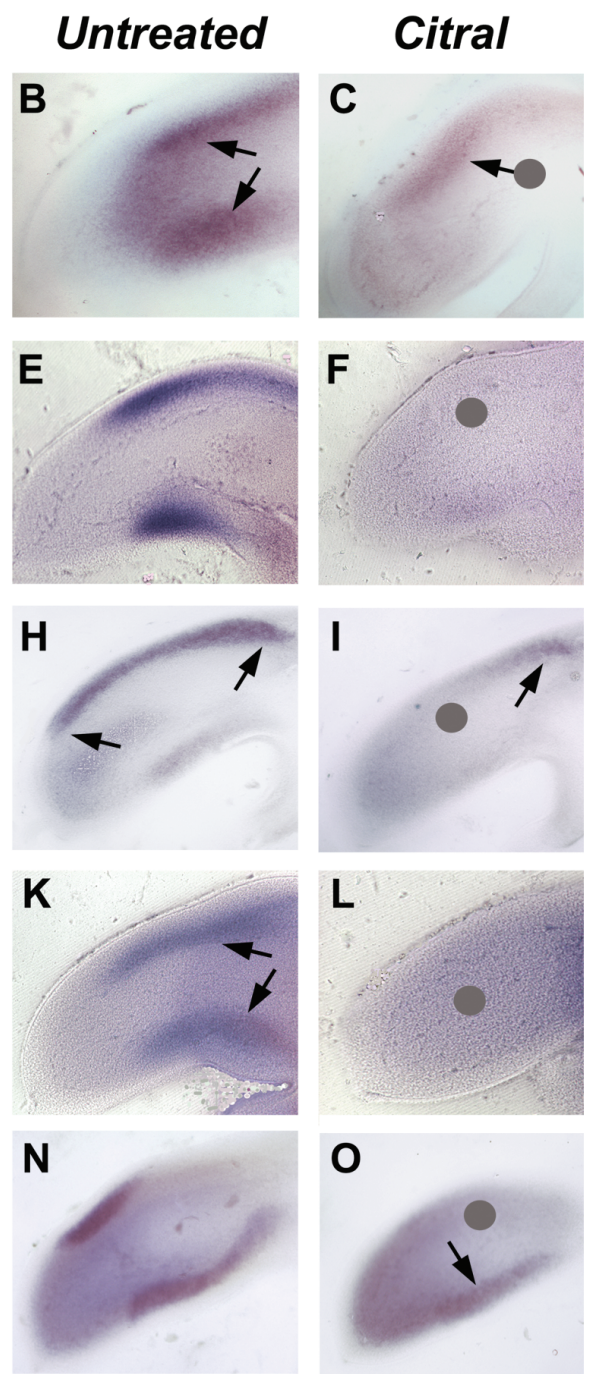
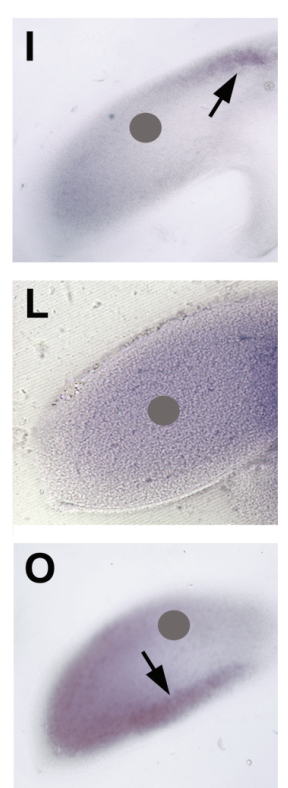

Fig. 1. Retinoic acid (RA) signalling is required at early stages of limb myogenesis. Views of transverse vibratome sections of stage 22 chick embryos before application of a bead of citral to the limb $(A, D, G, J, M)$ and at stage 25 after bead application and incubation $(B, C, E, F, H, I, K, L, N, O)$ to examine the effect on expression of Meox1 (A-C), Meox2 (D-F), Pax3 (GI), MyoD (J-L) and Myf5 (M-O). The citral treated limbs have been inverted for comparison with the untreated, contralateral limbs. The location of beads is identified by a grey circle. (B) Section of the untreated limb shows the normal expression of Meox 1 in the dorsal limb (upper black arrow) and the ventral limb (lower black arrow). (C) Treatment with citral has resulted in a down regulation of Meox 1 expression in the dorsal domain of the limb (black arrow) and a complete absence of expression in the ventral domain. (E) Normal Meox2 expression in the untreated contralateral limb bud. Meox2 expression is absent after treatment with citral (F). (H) Section of the untreated limb shows the normal expression of Pax3 in the dorsal premuscle mass (black arrows) and the ventral pre-muscle mass. (I) Treatment with citral has completely ablated Pax3 expression in the limb apart from a small domain in the dorsal pre-muscle mass (black arrow). (K) Normal MyoD expression in the dorsal and ventral pre-muscle masses (black arrows); after treatment with citral, MyoD expression is undetectable (L). (N) Expression of Myf5 in the untreated contralateral limb is in the dorsal and ventral pre-muscle masses. (0) Myf5 expression in the dorsal pre-muscle mass is absent after treatment with citral and expression in the ventral pre-muscle mass is reduced (black arrow) compared to the untreated control limb bud (N). that Meox 2 and Pax3are co-expressed in migrating myoblasts as they de-epithelialize from the dermomyotome, migrate into the limb bud mesenchyme and accumulate in the premuscle masses. Mice homozygous for a null mutation of Meox 2 have reduced muscle mass and an absence of specific muscles, and reduced Pax3 expression in limb muscle progenitors (Mankoo et al., 1999).

Retinoic acid (RA) is a low molecular weight (300 Da), signalling molecule that is known to affect pattern formation in vertebrate embryos including limb outgrowth and axial patterning. (reviewed by Maden, 2001). Many tissues such as the eye, hindbrain and spinal cord depend on a temporally and spatially regulated supply of $R A$. Without this supply of RA, many congenital defects occur. Paradoxically, exposure to this carefully regulated system by administering excess RA results in many defects similar to those generated by a lack of RA. Accumulated evidence has shown that inadequate levels (excess or deficiency) of RA cause a wide range of malformations in developing tissues. Deficiency of RA inhibits longitudinal bone growth (Wolbach et al., 1947) and excess RA also inhibits longitudinal bone growth by causing premature fusion of the epiphyseal growth plate (Pease, 1962, Standeven et al., 1996). In the hindbrain, retinoid excess targets predominantly the anterior rhombomeres (r1-4) whereby the anterior hindbrain was altered towards a more posterior segmental phenotype (Durston et al., 1989; Morriss-Kay et al., 1991; Conlon and Rossant, 1992; Marshall et al., 1992; Sundin and Eichele, 1992; Wood et al., 1994; Hill et al., 1995) and retinoid deficiency targets the posterior rhombomeres ( $\mathrm{r} 4-8)$ whereby they never differentiate (Gale et al., 1999; White et al., 2000). In the developing eye RA treated zebrafish and mouse embryos exhibited anophthalmia (Reijntjes et al., 2007b; Sulik et al., 1995) a condition also observed in RA deficiency (Wilson et al., 1953).

Endogenous all-trans-RA was first identified in the chick limb bud using HPLC (Thaller and Eichele, 1987) and components of the retinoid signalling pathway such as CRABP-II, RAR $\alpha, \operatorname{RAR} \beta$ are expressed in domains of the limb associated with muscle formation (Momoi, et al., 1992). In the chick limb bud, RALDH2, a RA generating enzyme, is expressed in the region of the presumptive muscle masses, vasculature and motor axons (Berggren et al., 2001); and in the mouse limb the establishment of pre-muscle masses, directed by HGF, has been proposed to be under the control of RALDH2 (Mic and Duester, 2003). RA receptors are expressed in muscle cells, RA receptors and MyoD up-regulate each other's transcriptional activity, these proteins interact physically and their transcriptional co-activation requires a RA receptor-MyoD complex that binds to MyoD DNA binding sites in muscle cells (Froeschlé et al., 1998). In chick, RARa is expressed in all limb bud cells at stage 20-22, just prior to or at the onset of myogenic commitment (Momoi et al., 1992).

Previous studies using cell lines have demonstrated that RA induces myogenic differentiation of a rat rhabomyosarcomaderived cell line, C2 myoblast cells and primary adult chick satellite cells, the cells that contribute to post-natal growth of muscle (Arnold et al., 1992; Albagli-Curiel et al., 1993; Halevy and Lerman, 1993). However, RA has also been shown to inhibit myosin heavy chain protein accumulation in mouse embryonic primary muscle cultures (Xiao et al., 1995) and depending on its concentration activate or repress myogenesis in the craniofacial mesenchyme (Langille et al., 1989). The physiological role of 
retinoids during limb myogenesis remains ambiguous as most studies have focused at late stages of differentiation and morphogenesis (Robson et al. 1994) or have used cultures of dissociated muscle: different concentrations of RA have been reported to increase or decrease MyoD expression in chick limb buds (Momoi et al., 1992). The subdivision of muscle masses and the development of individual tendons require interactions between muscle and tendon (Kardon, 1998; Rodriguez-Guzman et al., 2006) and components of the RA signalling pathways have been detected in the developing muscles and tendons of the mouse and chick limb (Abu-Abed et al., 2002; Berggren et al., 2001; Rodriguez-Guzman et al., 2006).

We have focused our attention on a possible role for RA in the early stages of myogenic commitment and differentiation. Firstly, we examined whether there is a requirement for RA signalling in myogenic commitment and/or differentiation, by use of an inhibitor of RA synthesis, citral, on beads applied to the developing chick limb where these genes are expressed. Secondly, we analysed the expression profiles of genes expressed in limb muscle progenitors (Meox2, Pax3, Myf5 and MyoD) in response to excess all-trans-RA (tRA) treatment. The absence of RA resulted in downregulation of expression of Meox2, Pax3, MyoD, Myf5 and Meox 1 and indicates a requirement for RA in the induction of myogenesis. We observed a differential sensitivity to RA dependent on the differentiation status of the cells: with a localised down regulation of Meox 2 and Pax3 expression in progenitors and a dramatic down-regulation in the expression of muscle differentiation genes $M y o D$ and $M y f 5$ and also of Meox1. Furthermore, both citral and RA treatments resulted in a decrease in myogenic differentiation. As myogenic differentiation takes place in conjunction with tendon differentiation we also investigated whether tendon progenitors in the limb respond in a similar fashion to RA as the myogenic precursors at stages when their development is occurring independently of each other. Taken together, these results suggest a complex sensitivity to RA concentrations during myogenesis and tendon development in the limb.

\section{Results}

\section{RA signalling is necessary for myogenic commitment and differentiation}

RA is known to produce diverse, dosage-dependent, effects on muscle differentiation, but it is not known whether myogenic differentiation requires $R A$ signalling. We exposed chick forelimb buds to the RA synthesis inhibitor citral (3,7-dimethyl-2,6octadienal), a reactive and volatile $\beta$-unsaturated aldehyde. Citral has been shown by HPLC of treated chick limb buds to inhibit RA synthesis (Tanaka et al., 1996) and in zebrafish, a RA reporter was down-regulated by citral (Perz-Edwards, et al., 2001). SM2 beads were incubated in $2.9 \times 10^{-3} \mathrm{M}$ citral in medium and were locally applied to the forelimb of a stage 22 chick embryo, when
Fig. 2. Retinoic acid differentially inhibits myogenic gene expression. Views of whole mount and transverse vibratome sections of stage 25 chick embryos after application of a bead of all-trans-RA to the limb to examine the effect on expression of Meox1 (A-C), Meox2 (D-F), Pax3 (G-I), MyoD (J-L) and Myf5 (M-O). White arrowheads mark the position of the beads $(A, D, G, J, M)$. The RA treated limb sections have been inverted for comparison with the untreated, contralateral limbs. The location of beads is identified by grey circles. (A) A dorsal view of an embryo which received a bead of all-trans-RA in the right limb bud. Meox1 expression appears down-regulated around the position of the bead compared to the untreated contralateral limb bud, left side. (B) Section through a tRA treated embryo shows the normal expression of Meox 1 in the untreated control limb bud. (C) Section of the RA treated limb bud reveals that Meox1 expression is down-regulated throughout the limb. (D) Whole mount embryo revealing that the expression of Meox2 has been down-regulated around the RA bead in the ventral region of the limb (compare to untreated limb). (E) A section through the embryo in D showing the normal expression of Meox2 in an untreated limb. Red arrows mark the ventral expression domain. (F) Treatment with a bead of $R A$ results in a less dramatic effect on the expression of Meox2 than the expression of Meox 1 in (C). This section shows localised down-regulation of Meox2 in the ventral domain corresponding to the position of the bead (compare red arrows in $F$ to red arrows in E). The affect of RA on the expression of $\mathrm{Pax} 3$ is not immediately apparent in a whole mount embryo (G) (right limb bud, white arrowhead). (H) A section through the embryo in (G) shows expression of Pax3 in the untreated limb bud. Black arrows indicate the normal expression in the dorsal premuscle mass. (I) Sectional analysis of RA treated limbs shows a localised effect on Pax3 in the proximity of the bead with expression downregulated distally in the dorsal pre-muscle mass domain (black arrow, compare with H). (J) Treatment with a bead of RA appears to completely ablate the expression of MyoD in the limb (compare expression in treated
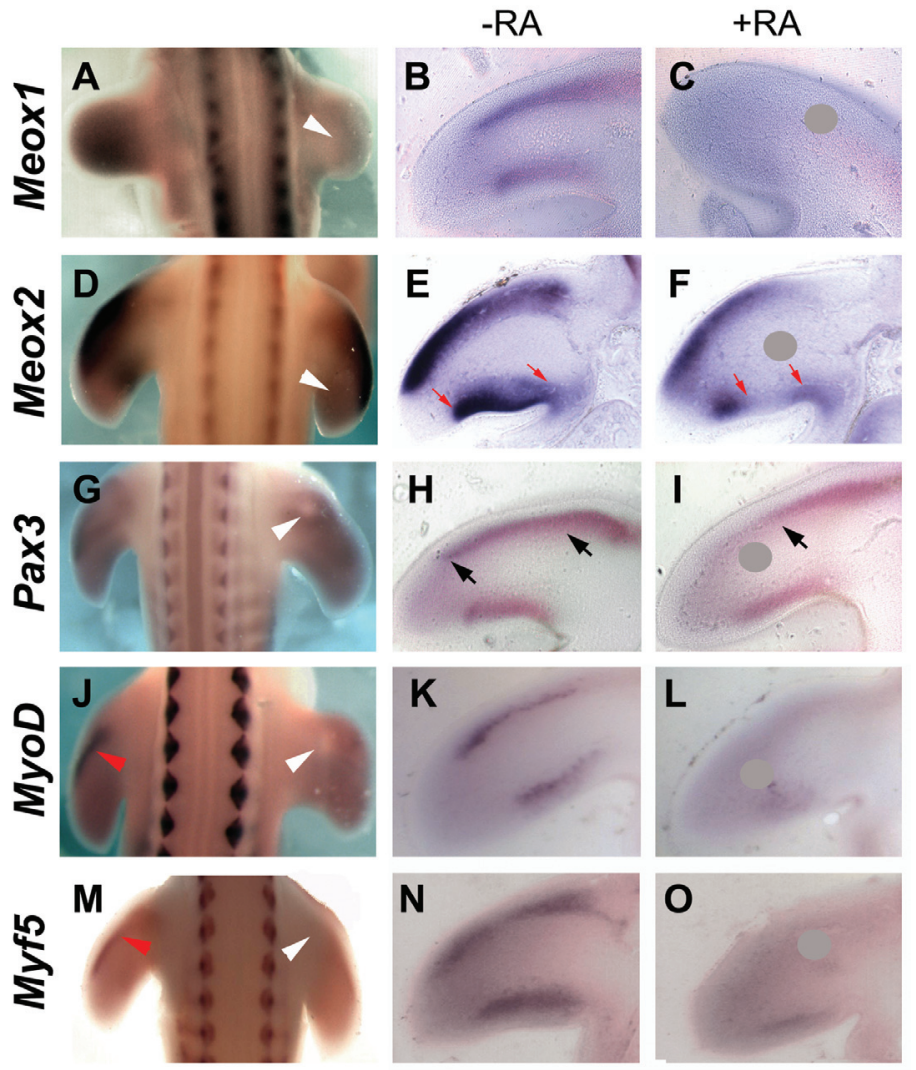

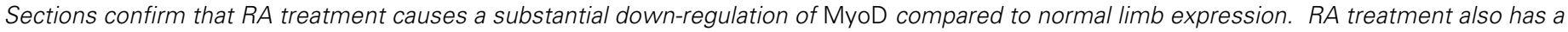

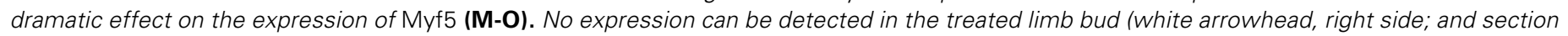
in O) compared to the untreated contralateral limb bud (red arrowhead, left side, and section in N). 

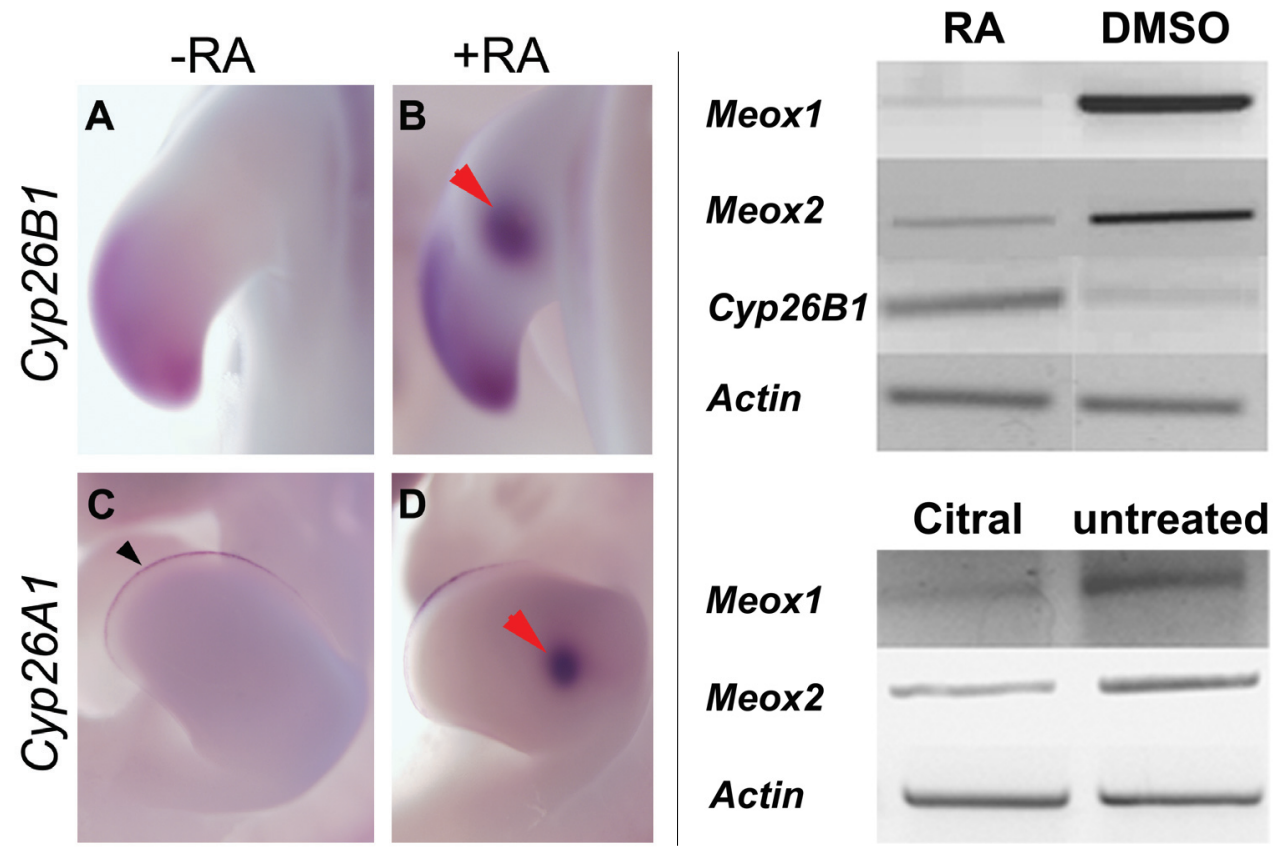

Fig. 3 (Left). Retinoic acid treatment induces ectopic Cyp26 expression. Views of the limb buds of stage 25 chick embryos to examine the effect of all-trans-RA on Cyp26 expression. Red arrowheads mark the position of the bead. (A) Dorsal view of the untreated contralateral limb bud showing normal Cyp26B1 expression in the progress zone. (B) In addition to the endogenous expression in the progress zone, a bead placed in the limb bud has up-regulated Cyp26B1 expression in the limb mesenchyme, right side. (C) Lateral view of an untreated limb showing normal Cyp26A1 expression in the apical ectodermal ridge. (D) RA treated, contralateral limb from (C) showing up-regulation of Cyp26A1 expression around the bead in the limb mesenchyme.

Fig. 4 (Right). Semi-quantitative gene expression analysis following citral and tRA treatment. Semiquantitative RT-PCR experiments on stage 25 chick forelimbs treated with beads of citral (lower left panel), control untreated contralateral limb (lower right panel), all-trans-RA (upper left panel) and control DMSO (upper right panel). The upper panel shows the results of Meox 1 with a decrease in expression after the addition of citral compared to the untreated control limb; a decrease in Meox 2 expression after citral treatment and no change in the expression of Actin after treatment with citral, compared to the untreated control. The upper panel shows the results for Meox 1 with a decrease in expression after the addition of all-trans-RA; a similar decrease in Meox2 after addition of all-trans-RA; an increase in expression of Cyp26B1 after the addition of all-trans-RA. There is no change in the expression of Actin with all-trans-RA.

myogenic differentiation has started, and examined by in situ hybridisation after overnight incubation. In vivo implantation of citral-beads arrested limb growth resulting in a decreased limb size compared to the untreated contralateral limb.

In citral treated limbs Meox 1 expression is present in the dorsal domain but is absent in the ventral domain local to the citral bead (Fig. 1 B,C, 2/2 embryos), while a reduced domain of dorsal expression persists. In contrast, inhibition of RA synthesis by citral has a dramatic affect on Meox2 expression affecting both dorsal and ventral domains resulting in a small region of greatly reduced expression remaining in the ventral part of the treated limb (Fig. 1 E,F, 2/2 embryos).

Compared to normal Pax3 expression in the pre-muscle masses, only a small domain of Pax3 remains in the dorsal premuscle mass after citral treatment (Fig. $1 \mathrm{H}, \mathrm{I})$. Citral treatment down-regulates expression of $M y O D$ in the dorsal and ventral premuscle masses (Fig. $1 \mathrm{~K}, \mathrm{~L}, 2 / 2$ treated embryos). Citral treatment also results in a down-regulation of expression of Myf5; however, in contrast to $M y o D$, the effect on $M y f 5$ expression is much less dramatic, with a localised reduction of expression (Fig.1 N,O. 3/ 3 embryos).

\section{$R A$ has a differential effect on gene expression in limb myogenic progenitors}

We investigated whether myogenic commitment and differentiation are sensitive to RA by administration of excess tRA, to the developing chick limb. For these experiments, we used local administration of AG 1-X2 beads soaked in $1.33 \times 10^{-2} \mathrm{M}$ tRA dissolved in DMS0. This dose has been found to duplicate the chick limb bud (Tickle et al. 1982). A tRA soaked bead was locally applied to the forelimb of a stage 22 chick embryo when myoblasts have migrated into the limb bud and the limbs were examined for gene expression by in situ hybridisation after overnight incubation. In all cases control beads which had been soaked in DMSO had no effect on the embryos either in terms of morphology or gene expression.

Meox 1 and Meox2 have overlapping and non-overlapping domains of expression in the limb bud (Reijntjes et al. 2007). tRA soaked beads caused a dramatic decrease in the limb expression pattern of Meox1 (Fig. 2 A-C, 9/11 treated embryos). Vibratome sectioning through the treated limb bud reveals that Meox1 expression is decreased throughout the limb in both dorsal and ventral muscle domains (Fig. 2C). In contrast, down-regulation of Meox2 expression after treatment with tRA is predominantly localised to the proximity of the bead (Fig. 2 D-F). Meox2 expression is down-regulated only in the ventral domain of the right forelimb bud in the region of the bead compared to the untreated control side (Fig. 2F, 9/9 embryos).

On initial observations, it appears that $P a x 3$ expression around the location of the bead is not affected by tRA treatment (Fig. 2G) but sectioning of this embryo reveals that compared to the normal expression in the dorsal and ventral pre-muscle masses, there is down-regulation of this gene in the dorsal pre-muscle mass in the proximity of the bead, compared to the control limb (Fig. 2I, 5/5 embryos), while more distant dorsal and the entire ventral expression domains remain unchanged.

$M y o D$ expression is induced in the premuscle masses at the onset of terminal differentiation. Expression of MyoD is significantly down-regulated throughout the limb bud by tRA treatment (Fig.2 J-L, 3/3 embryos). Sections through a tRA treated embryo demonstrate a small domain of reduced expression of MyoD remaining in the ventral pre-muscle mass (compare Fig. $2 \mathrm{~J}$ with 
2L). A similar effect is observed with Myf5 which is strongly downregulated by tRA beads when placed in the forelimb (Fig. $2 \mathrm{M}-0$, $4 / 4$ embryos). A small domain of reduced expression remains in the ventral pre-muscle mass after tRA treatment (Fig. 20).

These results demonstrate that myogenic progenitors in the limb have a differential response to RA, which reflects the differentiation status of the cells: Meox 2 and Pax 3 expression in undifferentiated progenitors shows only local down-regulation in regions of highest RA concentration, while both MyoD and Myf5 expression in differentiating myoblasts was reduced throughout the limb bud.

\section{Local concentrations of RA up-regulate expression of RA responsive genes in the limb}

To confirm that the concentration of tRA used in these experiments has a specific effect on genes involved in limb myogenesis and not a generalized effect on gene expression, in situ hybridisation was performed using the Cyp26A1 and Cyp26B1 anti-sense RNA probes after tRA treatment. Cyp26A1 and Cyp26B1 enzymes are members of the cytochrome P450 superfamily which catabolise RA to products such as 4-oxo-RA, 4-OHRA and 18- OH-RA (Fujii et al., 1997; White et al., 1997, 2000). Both genes are expressed in the developing chick limb, Cyp26A1 in the apical ectodermal ridge (AER) (Swindell et al., 1999) and Cyp26B1 in the distal mesenchyme of the progress zone (Reijntjes et al., 2003); and both are known to be inducible by RA (Abu-Abed et al., 1998; Fujii et al., 1997; Ray et al., 1997, Reijntjes et al., 2005; White et al., 1996; White et al., 1997). Cyp26B1 expression is up-regulated around the tRA bead in the forelimb mesenchyme, proximal to the progress zone, in $2 / 2$ embryos (Fig. 3B). Similarly, but to a lesser degree, a bead of tRA induces Cyp26A1 in the limb mesenchyme in $2 / 2$ embryos (Fig. 3D). This confirms the effects observed on the myogenic genes are not due to a non-specific down regulation of gene expression.

To again confirm the observations by in situ hybridisation, limb buds of stage 22 embryos were treated separately with beads soaked with $2.9 \times 10^{-3} \mathrm{M}$ citral, and $1.33 \times 10^{-2} \mathrm{MI}$ tRA or DMSO and incubated for 24 hours before collection and RNA extraction. Semi-quantitative RT-PCR was performed to analyse expression levels relative to those for actin. Meox1 and Meox2expression are down-regulated after treatment with citral compared to the untreated limb (Fig. 4, lower panel). Similarly, RT-PCR confirms that Meox1 and Meox2 RNA levels are down-regulated by tRA compared to DMSO and Cyp26B1 expression is up-regulated compared to DMSO control (Fig. 4, upper panel).

\section{Tendon differentiation is sensitive to RA signalling}

The development of muscle requires a coordinated differentiation of both muscle and tendons, although each tissue derives from different progenitors: the limb muscle from immigrant myoblasts originating from adjacent somites, and tendons from limb mesenchyme. We investigated whether tendon progenitors respond to RA in a similar manner as myogenic precursors, by analyzing expression of the transcription factor Scleraxis, which is expressed in all tendon progenitors in the limb (Schweitzer et al. 2001).

Scleraxis expression shows reduced expression in response to tRA (Fig. 5 A-C, in 3/3 embryos). Sections confirm that Scleraxis expression is reduced proximally in both the ventral and dorsal regions of the limb bud in the region of the bead (Fig. 5C). However, the reduction observed for Scleraxis expression is much less than seen for the myogenic genes. Citral inhibition of RA signalling resulted in an absence of Scleraxis expression in the dorsal domain of the limb and substantially reduced expression in the ventral domain (Fig. 5E, 5/5 embryos).

\section{RA treatment does not result in detectable changes in cell proliferation or cell death}

We next asked whether these treatments caused a decrease in cell proliferation, as RA can induce growth arrest in myogenic cells (Albagli-Curiel et al., 1993). The limbs of stage 22 embryos were treated with a bead of tRA, citral and DMSO at the same concentrations used for the in situ analyses and incubated for 24 hours before collection. At stage 25 dividing cells were detected using anti-phosphohistone $\mathrm{H} 3$ antibody staining on sections and were present in all treatments in similar numbers and distribution as the untreated, contralateral control limb, indicating that neither treatment with excess RA nor inhibition of RA signalling causes detectable changes in cell proliferation (data not shown).

RA administration has been shown to cause mouse limb defects partly by inducing massive cell death in developing limbs
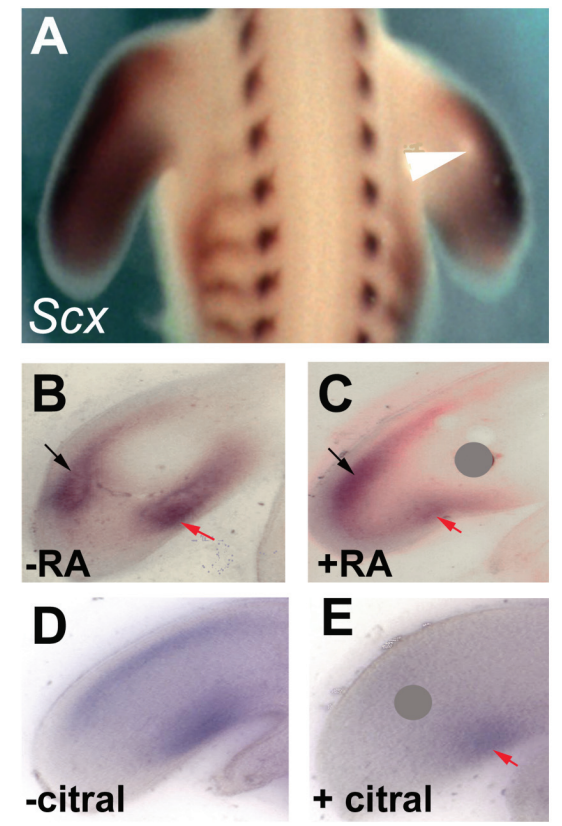

Fig. 5. Tendon development is responsive to retinoic acid signalling. The effect of RA (A-C) and citral (D-E) treatments on the expression of Scleraxis (SCX). The location of beads is identified with grey circles in (C,E). (A) A whole mount in situ hybridisation with Scleraxis reveals that compared with the untreated limb bud, there is localised down-regulation in the proximal limb bud around the position of the bead after RA treatment (white arrowhead). (B) A section through the embryo in $A$, shows the untreated limb bud with normal Scleraxis expression in the dorsal limb bud (black arrow) and the ventral limb bud (red arrow). (C) A section of the RA treated limb bud reveals that Scleraxis expression is reduced proximally both dorsally (compare to black arrow in B) and ventrally (compare to red arrow in B). Scleraxis expression is downregulated after treatment with citral compared with normal expression in the untreated limb (D), resulting in a residual small domain of expression in the ventral limb bud (E) (red arrow). 

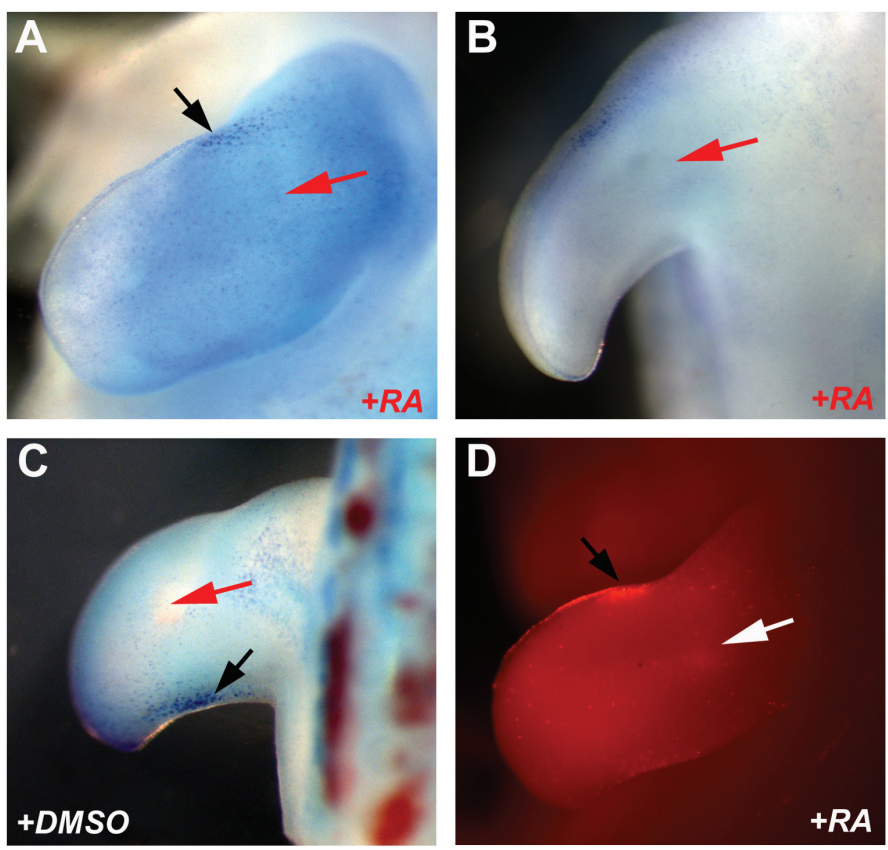

Fig. 6. Programmed cell death is not increased by application of tRA. Cell death was assayed by Nile blue sulphate (A-C) and LysoTracker Red (D) staining of stage 25 chick embryos right forelimbs. (A,D) Dorsal views of limbs to which a RA bead has been applied to the forelimb (white arrows) demonstrates that there is no cell death detected around the bead. (B) A ventral view of the same limb in (A) llimb has been inverted for ease of analysis) where no cell death can be detected around the location of the bead (white arrow). A DMSO control bead indicated by a red arrow (C) does not result in increased cell death. Cell death associated with sculpting of the limb can be detected in ( $A, C, D)$ (black arrow).

(Zakeri and Ahuja, 1994). In particular muscle morphogenesis in the distal limb is regulated by RA-induced apoptosis (RodriguezGuzman et al., 2006). Therefore, we performed cell death assays on the limbs of stage 25 embryos treated with beads of tRA and DMSO at stage 22. Nile blue sulphate staining reveals the characteristic pattern of apoptosis in the anterior necrotic zone and the ectoderm, sculpting the shape of the limb during limb development (Fig. 6A). A bead of tRA, used at the same concentration as used for the in situ analyses described above, does not induce apoptosis in the limb dorsally (Fig. 6A) or ventrally (Fig. $6 B$ ). LysoTracker Red staining after tRA treatment also reveals that administering tRA at this concentration does not result in increased apoptosis dorsally (Fig. 6D) or ventrally (not shown) compared to the control limbs.

\section{Muscle cell differentiation in micromass cultures is decreased by citral and RA treatments}

The effect of excess RA or inhibition of RA on terminal myogenic differentiation was examined by treating micromass cultures of stage 22 chick forelimbs with $1.75 \times 10^{-5} \mathrm{M}$ citral, $1 \times 10^{-}$ ${ }^{5} \mathrm{M}$ RA and DMSO. We determined the concentration of citral by using the lowest amount that did not result in cell death. The concentration of RA used was based on that used by others to study the response of myogenic differentiation to RA (Xiao et al., 1995). Fresh medium and factor were added every $48 \mathrm{hrs}$ and the cultures were examined on day 4 . Four cultures from each treatment group were pooled for analysis and the number of myosin HC positive cells as a proportion of the total number of cells was counted following citral and RA and treatments. (Cell counts per culture: DMSO, mean $=429 / 668$, S.D. $=71$; citral, mean $=230 / 571$, S.D. $=24 ;$ RA, mean $=245 / 705$, S.D. $=88$ ) Therefore, compared to controls, citral and RA treatment result in myogenic inhibition by $47 \%$ and $43 \%$ respectively.

\section{Discussion}

RA signalling is important in the morphogenesis of many embryological systems including the hindbrain, the heart and the eye and but its role during early stages of myogenic specification and differentiation in the limb is unknown. We analysed the effect of both inhibiting RA synthesis and applying excess RA on the limb myogenic progenitors, post migration and at the onset of differentiation.

In particular we are interested in deciphering which signals that are involved in differentiation and morphogenesis of limb muscles are mediated via Meox homedomain transcription factors. Previously we have reported on the role of the Meox homeobox gene family in limb muscle development (Mankoo et al., 2003), and we have demonstrated that Meox2 is a component of the genetic cascade that regulates skeletal myogenesis in the limb (Mankoo et al., 1999); and in the chick limb these genes are differentially expressed: Meox 2 is expressed in a broader domain in the dorsal and ventral limb overlapping Pax3, whereas Meox 1 expression is deeper within the limb and overlaps with $M y o D$, and there is a narrow region of overlap of Meox1 and Meox2 (Reijntjes et al., 2007a). In the work described here, we have studied whether Meox expression is responsive to RA signalling in the developing chick limb.

Several studies have investigated the effect of RA on myogenic differentiation in the limb. Most studies have focused at late stages of differentiation and morphogenesis (Robson et al. 1994) or have used cultures of dissociated muscle: different concentrations of RA have been reported to increase or decrease MyoD expression in chick limb buds (Momoi et al., 1992). Both citral and RA treatments altered development of distal limb muscle bellies, demonstrating that muscle-tendon interactions are mediated in part by apoptosis regulated by RA signalling (Rodriguez-Guzman et al., 2006). Conditionally rescued RALDH2 mutant mouse embryos showed abnormal migration of limb muscle precursors in the forelimb, but expressed $M y o D$ at E11.5, which could be interpreted as evidence for there being no requirement for RA for myogenic differentiation (Mic and Duester, 2004). However, in that study there was rescue by application of RA to pregnant mothers, which leads to the possibility that RA-dependent gene expression had been initiated before the RA was cleared. Moreover, the rescued limb was small and the MyoD expression occupied a much smaller domain than control limbs. Here we show that loss of RA signalling within the limb does affect differentiation of myogenic progenitors. Treatment with the RA inhibitor citral resulted in down-regulation of expression of myogenic genes in both progenitor cells (Pax3 and Meox2, Meox2 down-regulation was greater than that of $P a x 3)$ and myoblasts committed to differentiation ( $M y f 5$ and $M y o D, M y o D$ down-regulation was greater than that of $M y f 5$ ). These results are consistent with the down-regulation in expression of neural $P a x 3$ and the 
myogenic differentiation gene Myogenin in somites in the absence of RA, as reported in the vitamin A deficient quail (Wilson et al., 2004; Maden et al., 2000). Additionally, in vivo studies in zebrafish embryos demonstrated that RA signalling is required for onset of myogenic differentiation in somites (Hamade et al., 2006). The decreased expression of $M y o D$ may be direct, as MyoD expressing cells respond to RA and physically interact with RXRs to form DNA binding complexes (Froeschle et al. 1998), or may be a consequence of down regulation of Pax3 and Myf5, although $M y o D$ induction in Meox2 mutant limbs occurs normally when Pax3 and Myf5 expression is reduced (Mankoo et al., 1999). In summary, these data demonstrate that RA is required for myogenic commitment and differentiation, but the differential response of the myogenic genes indicates the requirement for RA signalling is complex.

Analysis of tRA treated forelimb buds indicates that Meox1 expression is strongly down-regulated throughout the limb bud whereas Meox2 expression was less affected, with down-regulation only occurring around the location of the tRA soaked bead. This supports overlapping and unique functions for each gene within their expression domains, with Meox2 being expressed in the progenitor cells and Meox 1 in deeper layers of differentiated cells. Interestingly, Meox 1 and Meox 2 expression is also altered differentially in explanted neural crest in response to RA, Meox1 expression is up-regulated and Meox2 expression is down-regulated (Williams et al., 2004), indicating that response of Meox genes to $\mathrm{RA}$ is also context dependent, resulting in unique functions for these closely related genes.

Application of excess tRA induced localised down-regulation of Pax3 in the chick limb in a manner similar to Meox2. The coexpression of Meox 2 and Pax 3 in the chick limb bud (Reijntjes et al., 2007a) and in migrating limb myoblasts in the mouse, and the down-regulation of $P$ ax 3 expression in these cells in the absence of Meox2 (Mankoo et al. 1999); strongly implies a role for Meox2, along with $\mathrm{Pax} 3$, in muscle cell specification. In a manner similar to its affect on Meox1, excess tRA induced strong down-regulation of Myf5 and MyoD expression in the developing limb bud. The strong effect of both citral and tRA resulting in a broad downregulation of gene expression indicates a greater sensitivity to the concentration of citral and tRA, as it is assumed there is a decreasing concentration of chemical away from the bead. Localised down-regulation, conversely, indicates that relatively high concentrations are required to produce an effect. Both citral and RA treatment resulted in a severe decrease in the formation of myosin positive myotubes. The differential sensitivity to RA shown by Pax3 expressing progenitors and Myf5 expressing myoblasts is noteworthy, as $\mathrm{Pax} 3$ is known to directly regulate Myf5 expression in the hypaxial somite and limb muscle progenitors (Bajard et al., 2006); and indicates a rapid change in the RA response as cells switch from a progenitor state to differentiation. The expression of $\mathrm{RA}$ receptors in muscle progenitors (Froeschle et al., 1998) suggests the effects of RA on myogenesis we observed are direct

The negative effect of RA on Myf5 and MyoD expression has been observed following RA treatment on primary muscle cultures prepared from dissociated neonatal mouse hind legs, $M y o D$ transcripts were reduced and Myf5 and MRF4 transcripts were undetectable (Xiao et al., 1995). Using primary dissociated cultures of $13.5 \mathrm{dpc}$ mouse limb buds and neonatal hind leg muscles treated with $10^{-5} \mathrm{M}$ RA, these authors also demonstrated RA treatment resulted in a dramatic loss of MyHC expression. Similarly, in chick, micromass cultures of cells prepared from stage 20 forelimb buds, treated with RA resulted in fewer myogenic cells differentiating (Robson et al., 1994). In the work described here, we show that RA treatment resulted in a $43 \%$ decrease in $\mathrm{MyHC}$ positive cells in chick micromass cultures. These data strongly suggest that differentiating limb myoblasts have a greater sensitivity and therefore a different response to RA signalling than progenitors. Similarly myogenic differentiation showed a similar response in the somites of vitamin A deficient quail embryos, in which RA is absent, Myogenin expression was down-regulated but Myf5 expression was not (Maden et al., 2000). This is also supported by the observation that the myogenic response of rhabdomyosarcoma cells to RA is dependent on their differentiation status (Ricaud et al., 2005), and a relationship between differentiation state and sensitivity to RA has also been reported in ovarian cancer cells (Caliaro et al., 1994).

$\mathrm{RA}$ receptors bind their cognate binding sites via heterodimerisation with RXR proteins. We analysed the number of $R X R$ binding sites in 200 bp of sequence upstream and $100 \mathrm{bp}$ downstream of the transcription start site of each mouse homologue of the myogenic genes using Genomatix Matlnspector software (Cartharius et al., 2005). Interestingly, the number of $\mathrm{RXR}$ sites shows a positive correlation with sensitivity to citral treatment $(M y o D>M e o x 2>P a x 3>$ Meox1>Myf5), however, this correlation does not extend to the response to tRA treatment; indicating that RA function at early stages of myogenesis is complex.

Loss of gene expression was not due to non-specific effects on cell death as shown by cell death analyses, ability to induce Cyp26 expression and the differential response to excess RA. Moreover, the tRA induced ectopic expression of Cyp26A1 and Cyp26B1 in the limb bud mesenchyme is novel as it had been previously thought that excess tRA could only induce Cyp26 expression in other Cyp26 expression domains, but not in regions where the Cyp26s are never expressed, for example, ectopic Cyp26A1 expression can be induced in the developing vasculature, a site of Cyp26B1 expression (Reijntjes et al., 2005).

The development of muscle requires closely integrated differentiation of both myogenic and muscle-associated connective tissue precursors. RALDH2, the major RA generating enzyme is expressed in the connective tissue precursors, motor neurons and vasculature in the chick limb, although not within myoblasts (Berggren et al. 2001). RA signalling components have been detected in the developing tendons and muscle in mouse (AbuAbed et al., 2002) and chick limbs (Rodriguez-Guzman et al., 2006) demonstrating RA plays a role at later stages of tendon development. RA has been implicated in regulating morphogenesis of distal muscle and tendons by an apoptosis-mediated mechanism (Rodriguez-Guzman et al., 2006). However, the role of RA on tendon progenitors is unknown. We observed downregulation of expression of the tendon-specific gene Scleraxis in response to both excess RA and inhibition of RA signalling. Significantly, this loss of Scleraxis expression is independent of the effects of RA on muscle as myogenic and tendon progenitors initially develop independently (Kardon, 1997), suggesting a mechanism that coordinates the differentiation of these tissues.

To conclude, we have shown that RA signalling is essential for 
maintenance of premyogenic cells and myogenic commitment within the limb bud. Excess RA signalling inhibits myogenic differentiation suggesting that a gradient of RA activity controls the rate of myogenic commitment. We show that $R A$ signalling is essential for the early stages of myogenesis and tendon development, RA could also modulate the rate of myogenic differentiation by interactions with tendons and the vascular system at later stages of morphogenesis. We have shown that both inhibition and excess RA can negatively effect myogenic differentiation emphasizing the importance of an exquisitely controlled local concentration of RA. Moreover we have shown the response to RA is dependent on the state of differentiation of limb muscle precursors.

\section{Materials and Methods}

\section{Embryos}

Fertilised hens eggs (mixed flock, Henry Stewart and Co. Ltd., Louth, Lincolnshire) were incubated in a humidified atmosphere at $37^{\circ} \mathrm{C}$. Embryos were staged according to Hamburger and Hamilton (Hamburger and Hamilton, 1951).

\section{Experimental manipulation of the forelimb}

All-trans-RA (Sigma) was dissolved in dimethyl sulfoxide (DMSO), (Sigma-Aldrich, USA) to a concentration of $1.33 \times 10-2 \mathrm{M}$ and incubated in analytical grade anion exchange resin beads AG1-X2, 100-200 Mesh Formate Form (Bio-RA). To visualise the beads $1 \mathrm{ml}$ of Dulbecco's MOD eagle Medium (Gibco) was added. SM2 beads (BioRad) were incubated in $2.9 \times 10-3 \mathrm{M}$ Citral (Fluka) in M16 medium (Sigma). Eggs were fenestrated at 3.5 days after incubation and beads were implanted in the developing right forelimb of stage 22 embryos. The embryos were then incubated for $24 \mathrm{~h}$ at $37^{\circ} \mathrm{C}$ and then samples were processed for in situ hybridisation, or RNA extraction or immunostaining. The all-trans-RA experiments were controlled by parallel experiments implanting DMSO soaked beads.

\section{Whole-mount in situ hybridization and sectioning}

Digoxigenin (Roche) labelled antisense RNA probes for Meox 1, Meox2 and Scleraxis were prepared as described (Reijntjes et al., 2007). Pax3, $M y o D$ and $M y f 5$ antisense-probes were prepared by Philippa FrancisWest and Cyp26A1 and Cyp26B1 probes were prepared as previously described (Reijntjes et al., 2005). Whole-mount in situ hybridisation was carried out using standard procedures, prehybridisation and hybridisation was carried out at $70^{\circ} \mathrm{C}$ with a probe concentration of $1 \mu \mathrm{g} / \mathrm{ml}$ and visualised with digoxigenin antibodies conjugated to alkaline phosphatase reacted with NBT/BCIP purple (Roche). Embryos were embedded in $3.6 \mathrm{ml}$ vibratome embedding mix (gelatine type A, egg albumin, Sigma, sucrose, BDH), incubated for $2 \mathrm{~h}$ at room temperature and then $400 \mu \mathrm{l}$ glutaraldehyde (Sigma) was added). Sections were cut at $80 \mu \mathrm{m}$ on a vibratome (Leica VT 1000S), placed on glass microscope slides and mounted in glycerol.

\section{Semiquantitative reverse transcription-PCR analysis}

RNA was isolated from all-trans-RA, DMSO and Citral treated and untreated forelimbs by the guanidinium thiocyanate method of Chomczynski and Sacchi (1987). For all semiquantitative RT-PCR reactions, single-stranded cDNA was synthesised from $1 \mu \mathrm{g}$ of forelimb RNA. The cDNA synthesis was achieved by using cloned AMV 1st strand cDNA synthesis kit (Invitrogen). One microgram of total RNA and $1 \mu$ I Oligo(dT)20 primer was heated for $5 \mathrm{~min}$ at $65^{\circ} \mathrm{C}$ and then reverse transcribed at $50^{\circ} \mathrm{C}$ for $1 \mathrm{~h}$ using $4 \mu \mathrm{l} 5 \mathrm{x}$ cDNA synthesis buffer, $1 \mu \mathrm{l}$ DTT (100 nM), $1 \mu \mathrm{l}$ RNaseOUT $(40 \mathrm{U} / \mu \mathrm{l})$ and $1 \mu \mathrm{l}$ cloned AMV reverse transcriptase (15 units $/ \mu \mathrm{l})$ in a $20 \mu \mathrm{l}$ reaction. The PCR reaction was carried out using $2 \mu \mathrm{l}$ of the retrotranscription reaction in a final volume of $50 \mu \mathrm{l}$, containing $10 \mathrm{x}$
PCR buffer, $200 \mu \mathrm{M}$ each dNTPs, $0.2 \mu \mathrm{M}$ each primer and 1.25 units of Taq DNA polymerase (New England Biolabs).

Actin and Cyp26B1 primers were designed as previously described (Reijntjes et al., 2005). For Meox1 primers were designed using GENBANK accession no. NM_204765 to generate a 403-bp product, for Meox2 primers were designed from NM_001005427 to generate a 368-bp product. The forward and reverse primers were, respectively:

Meox1: 5'-TGAATTCTCAGCCTCCTGCT-3' and 5'-TCTCCTGAGCCTTGTCAGGT-3';

Meox2: 5'-TCCCTCAGATGTCGTCTCCT-3' and 5'-ATCTCCTCAGCCTGGTCAAA-3'.

The actin cDNA was co-amplified in each experiment to verify equal amounts of cDNA in the samples. The amplification reaction was initiated by incubation of PCR samples at $94^{\circ} \mathrm{C}$ for 2 min followed by the cyclic program, $94^{\circ} \mathrm{C}$ for $30 \mathrm{~s}, 58^{\circ} \mathrm{C}$ for $30 \mathrm{~s}$ and $72^{\circ} \mathrm{C}$ for $1 \mathrm{~min}$ for 35 cycles for Cyp26B1 amplification, $94^{\circ} \mathrm{C}$ for $30 \mathrm{~s}, 50^{\circ} \mathrm{C}$ for $30 \mathrm{~s}$ and $72^{\circ} \mathrm{C}$ for $1 \mathrm{~min}$ for 38 cycles for $M e o x 1$ and $94^{\circ} \mathrm{C}$ for $30 \mathrm{~s}, 55^{\circ} \mathrm{C}$ for $30 \mathrm{~s}$ and $72^{\circ} \mathrm{C}$ for 1 min for 32 cycles for Meox2. For each primer set, an increasing number of PCR cycles were performed with otherwise fixed conditions to determine the optimal number of cycles to be used. PCR reactions were performed twice with two separate cDNA pools of treated and untreated forelimb buds and each gene product was verified by sequencing.

\section{Cell proliferation and cell death}

Paraffin-wax-embedded tissue sections were processed and mounted on glass slides. To label proliferating cells a rabbit polyclonal antibody to the phosphorylated serine 10 residue of histone $\mathrm{H} 3$ (anti-phospho-H3) was used (BD Pharmingen) as a marker of cells entering mitosis (Clayton et al., 2000). The antibody was used at a concentration of $1: 8000$ followed by a Vector ABC Elite kit (Vector Laboratories) to visualise immunoreactivity.

Nile blue sulphate (NBS) staining is a vital stain that is sequestered into apoptotic bodies and phagolysosomes found in cells neighbouring apoptotic cells (Allen et al., 1997). All-trans-RA and DMSO treated stage 25 embryos were dissected from extraembryonic membranes and transferred to 1:50,000 NBS in lactated Ringer's solution (Kotch et al., 1992) and incubated at $37^{\circ} \mathrm{C}$ for $30 \mathrm{~min}$. After staining embryos were rinsed in cold Ringer's solution and photographed. LysoTracker Red (LTR) staining. LTR (Molecular Probes) concentrates in membrane bound, acidic compartments of cells indicating regions of high phagocytosis and lysosomal activity correlating to apoptosis activity (Zucker et al., 1998, 1999). Embryos were dissected in Hanks and transferred to 24-well plates containing 1:100 LTR in fresh Hanks warmed to $37^{\circ} \mathrm{C}$. This was removed and replaced with 1:3 LTR in Hanks, plates were covered and incubated at $37^{\circ} \mathrm{C}$ for $30 \mathrm{~min}$. After staining embryos were rinsed $4 \times 5$ min with Hanks and fixed overnight in $4 \%$ paraformaldehyde (Sigma) at $4{ }^{\circ} \mathrm{C}$. Embryos were rinsed in PBS, dehydrated in $100 \% \mathrm{MeOH}$ and viewed under fluorescence in $\mathrm{MeOH}$.

\section{Micromass culture}

The ectoderm of stage 22 chick forelimbs was removed following treatment with cold trypsin. The mesenchyme was then disaggregated and the cells were suspended in modified F-12 tissue culture medium (Gibco advanced DMEM/F12 + 2 mM L-glutamine +100 units $/ \mathrm{ml}$ penicillin, $100 \mu \mathrm{g} / \mathrm{ml}$ streptomycin $+10 \%$ foetal calf serum (Gibco). The cells were plated out in $10 \mu \mathrm{l}$ drops at a final density of $2 \times 10^{5}$ cells per $10 \mu \mathrm{l}$. The cultures were then incubated at $37^{\circ} \mathrm{C}$ with $5 \% \mathrm{CO}_{2}$ for 1 hour and then flooded with modified F-12 medium. RA was added to the medium resulting in a final concentration of $10^{-5} \mathrm{M}$, DMSO was added at equivalent amounts to RA $(1 \mu \mathrm{l} / \mathrm{ml})$ and citral added in a final concentration of 1.75 $\times 10^{-5} \mathrm{M}$. Medium, plus reagents, was replaced every $48 \mathrm{hrs}$. On day 4 after plating, cells were fixed for immunohistochemical staining.

\section{Immunohistochemistry}

Cells were washed three times with PBS and then fixed on the plates 
with 4\% PFA for $10 \mathrm{~min}$. After two washes with PBS, non-specific proteins were blocked by incubation with $\mathrm{PBS} / 5 \%$ horse serum for 5 mins. Pan myosin MyHC antibody (a gift from Simon Hughes) was diluted with PBS/ $2 \%$ horse serum and added onto the plates and incubated overnight at $4^{\circ} \mathrm{C}$ and then washed 3 times with PBS. Subsequent incubation was performed at $4^{\circ} \mathrm{C}$ overnight with peroxidase labelled anti-mouse IgG $(\mathrm{H}+\mathrm{L})$ secondary antibody (Vector laboratories), diluted 1 in 500 in PBS/ $2 \%$ horse serum. Substrate solution made from DAB tablets (Sigma) following manufacturer's instructions was used to stain the plates for 5 min. Staining was recorded with microscopic photography and cell counts performed for each treatment (four separate micromass culture samples each).

\section{Acknowledgements}

This work was supported by the BBSRC and MYORES FP6 Network of Excellence. We thank Professor Malcolm Maden for technical assistance and reagents; and also the helpful comments of anonymous reviewers.

\section{References}

ABU-ABED, S.S., BECKETT, B.R., CHIBA, H., CHITHALEN, J.V., JONES, G., METZGER, D., CHAMBON, P.and PETKOVICH, M. (1998). Mouse P450RA (CYP26) expression and retinoic acid-inducible retinoic acid metabolism in F9 cells are regulated by retinoic acid receptor gamma and retinoid $X$ receptor alpha. J Biol Chem 273: 2409-2145.

ABU-ABED, S.S., MACLEAN, G., FRAULOB, V., CHAMBON, P., PETKOVICH, M. and DOLLE, P. (2002). Differential expression of the retinoic acid-metabolizing enzymes CYP26A1 and CYP26B1 during murine organogenesis. Mech Dev 110: 173-177.

ALLEN, R.T., HUNTER, W.J. and AGRAWAL, D.K. (1997). Morphological and biochemical characterization and analysis of apoptosis. J Pharmacol Toxicol Meth 37: 215-228.

ARNOLD, H.H., GERHAZ, C.D., GABBERT, H.E. and SAMINEN, A. (1992). Retinoic acid induces myogenin synthesis and myogenic differentiationin the rat rhabdomyosarcoma cell line BA-Han-1C. J Cell Biol 118: 877-887.

ALBAGLI-CURIEL, O., CARNAC, G., VANDROMME, M., VINCENT, S., CREPIEUX, P. and BONNIEU, A. (1993). Serum-induced inhibition of myogenesis is differentially relieved by retinoic acid and triodothyronine in $\mathrm{C} 2$ murine muscle cells. Differentiation 52: 201-210.

BAJARD, L., RELAIX, F., LAGHA, M., ROCANCOURT, D., DAUBAS, P. and BUCKINGHAM, M.E. (2006). A novel genetic hierarchy functions during hypaxial myogenesis: Pax3 directly activates Myf5 in muscle progenitor cells in the limb. Genes Dev 20: 2450-2564.

BERGGREN, K., EZERMAN, E.B., MCCAFFERY, P. and FOREHAND, C.J. (2001). Expression and regulation of the retinoic acid synthetic enzyme RALDH-2 in the embryonic chicken wing. Dev Dyn 222: 1-16.

BOBER, E., FRANZ, T., ARNOLD, H.H., GRUSS, P. and TREMBLAY, P. (1994). Pax-3 is required for the development of limb muscles: a possible role for the migration of dermomyotomal muscle progenitor cells. Development 120: 603612.

CALIARO, M.J., MARMOUGET, C., GUICHARD, S., MAZARS, P., VALETTE, A., MOISAND, A., BUGAT, R. and JOZAN, S. (1994). Response of four human ovarian carcinoma cell lines to all-trans retinoic acid: relationship with induction of differentiation and retinoic acid receptor expression. Int J Cancer 56: 743748.

CARTHARIUS, K., FRECH, K., GROTE, K., KLOCKE, B., HALTMEIER, M., KLINGENHOFF, A., FRISCH, M., BAYERLEIN, M. and WERNER, T. (2005). MatInspector and beyond: promoter analysis based on transcription factor binding sites. Bioinformatics 21: 2933-2942.

CHEVALLIER, A., KIENY, M. and MAUGER A. (1977). Limb-somite relationship: origin of the limb musculature. J Embryol Exp Morph 41: 245-258.

CHRIST, B., JACOB, H.J. and JACOB, M. (1977). Experimental findings on muscle development in the limbs of the chick embryo. Verh Anat Ges 71: 1231-1237.

CHOMCZYNSKI, P. and SACCHI, N. (1987). Single-step of RNA isolation by acid guanidinium thiocynate-phenol-chloroform extraction. Anal Biochem 162: 156 159.

CONLAN, R.A. and ROSSANT, J. (1992). Exogenous retinoic acid rapidly induces anterior ectopic expression of murine Hox-2 genes in vivo. Development 116: 357-368.

DURSTON, A.J. TIMMERMANS, J.P., HAGE, W.J., HENDRIKS, H.F., DE VRIES, N.J., HEIDEVELD, M. and NIEUWKOOP, P.D. (1989). Retinoic acid causes an anteroposterior transformation in the developing central nervous system. $\mathrm{Na}$ ture 340: 140-144

FROESCHLÉ, A., ALRIC, S., KITZMANN, M., CARNAC, G., AURADÉ, F., ROCHETTE-EGLY, C. and BONNIEU, A. (1998). Retinoic acid receptors and muscle b-HLH proteins: partners in retinoid-induced myogenesis. Oncogene 16: 3369-3378.

FUJII, H., SATO, T., KANEKO, S., GOTOH, O., FUJII-KURIYAMA, Y., OSAWA, K., KATO, S. and HAMADA, H. (1997). Metabolic inactivation of retinoic acid by a novel P450 differentially expressed in developing mouse embryos. EMBO J 16 4163-4173.

GALE, E., ZILE, M. and MADEN, M. (1999). Hindbrain respecification in the retinoid-deficient quail. Mech Dev 89: 43-54.

GOULDING, M., LUMSDEN, A. and PAQUETTE, A.J. (1994). Regulation of Pax3 in the dermomyotome and its role in muscle development. 1994. Development 120: $957-971$.

GROSS, M.K., MORAN-RIVARD, L., VELASQUEZ, T., NAKATSU, M.N., JAGLA K. and GOULDING, M. (2000). Lbx1 is required for muscle precursor migration along a lateral pathway into the limb. Development 127: 413-424.

HALEVY, O. and LERMAN O. (1993). Retinoic acid induces adult muscle cell differentiation mediated by the retinoic acid receptor-alpha. J Cell Physiol 154 566-572

HAMADE, A., DERIES, M., BEGEMANN, G., BALLY-CUIF, L., GENÊT, C., SABATIER, F., BONNIEU, A., and COUSIN, X. (2006). Retinoic acid activates myogenesis in vivo through Ffg8 signalling. Dev Biol 289: 127-140.

HAMBURGER, V. and HAMILTON, H.L. (1951). A series of normal stage sin the development of the chick embryo. J Morphol 88: 49-92.

HAYASHI, K. and OZAWA, E. (1995). Myogenic cell migration from somites is induced by tissue contact with medial region of the presumptive limb mesoderm in chick embryos. Development 121: 661-669.

HILL, J., CLARKE, J.D., VARGESSON, N., JOWETT, T. and HOLDER, N. (1995). Exogenous retinoic acid causes specific alterations in the development of the midbrain and hindbrain of the zebrafish embryo including positional respecification of the Mauthner neuron. Mech Dev 50: 3-16.

JACOB, M., CHRIST, B. and JACOB, H.J. (1978). On the migration of the myogenic stem cells into the prospective wing region of chick embryos. A scanning and transmission electron microscope study. Anat. Embryol. (Berl.) 153: 179-193.

KARDON, G. (1998). Muscle and tendon morphogenesis in the avian hind limb. Development 125: 4019-4032.

KOTCH, L.E., DEHART, D.B. and ALLES, A.J., (1992). Pathogenesis of ethanolinduced limb reduction defects in mice. Teratology 46: 323-332.

LANGILLE, R.M., PAULSEN, D.F. and SOLURSH, M. (1989). Differential effects of physiological concentrations of retinoic acid in vitro on chondrogenesis and myogenesis in chick craniofacial mesenchyme. Differentiation 40: 84-92.

MADEN, M., GRAHAM, A., ZILE, M. and GALE, E. (2000). Abnormalities of somite development in the absence of retinoic acid. Int J Dev Biol 44: 151-159.

MADEN, M. (2001). Retinoid signalling in the development of the central nervous system. Nature Rev Neurosci 3: 843- 853

MANKOO, B.S., COLLINS, N.S., ASHBY, P., GRIGORIEVA, E., PEVNY, L.H., CANDIA, A., WRIGHT, C.V., RIGBY, P.W. and PACHNIS, V. (1999). Mox2 is a component of the genetic hierarchy controlling limb muscle development. Nature 400: 49-73.

MANKOO, B.S., SKUNTZ, S., HARRIGAN, I., GRIGORIEVA, E., CANDIA, A. WRIGHT, C.V., ARNHEITER, H., P.W. and PACHNIS, V. (2003). The concerted action of Meox homeobox genes is required upstream of genetic pathways essential for the formation, patterning and differentiation of somites. Development 130: 4655-4664.

MARSHALL, H., NONCHEV, S., SHAM, M.H., MUCHAMORE, I., LUMSDEN, A and KRUMLAUF, R. (1992). Retinoic acid alters hindbrain Hox code and 


\section{S. Reijntjes et al.}

induces transformation of rhombomeres $2 / 3$ into a 4/5 identity. Nature 360 : 737741.

MIC, F.A. and DUESTER, G. (2003). Patterning of forelimb bud myogenic precursor cells requires retinoic acid signaling initiated by Raldh2. Dev Biol 264: 191-201.

MOMOI, T., MIYAGAWA-TOMITA, S., NAKAMURA, S., KIMURA, I. and MOMOI, M. (1992). Retinoic acid ambivalently regulates the expression of MYOD1 in the myogenic cells in the limb buds of the early developmental stages. Biochem and Biophy Res Comm 187: 245-253.

MORRISS-KAY, G.M., MURPHY, P., HILL, R.E. and DAVIDSON, D.R. (1991). Effects of retinoic acid excess on expression of Hox-2.9 and Krox-20 and on morphological segmentation in the hindbrain of mouse embryos. EMBO J 10: 2985-2995.

PEASE, C.N. (1962). Focal retardation and arrestment of growth of bones due to vitamin A intoxication. J Am Med Assoc 182: 980-985.

PERZ-EDWARDS, A., HARDISON, N.L and LINNEY E. (2001). Retinoic acidmediated gene expression in transgenic reporter zebrafish. Dev Biol 229: 89101.

RAY, W.J., BAIN, G., YAO, M. and GOTTLIEB, D.I. (1997). CYP26, a novel mammalian cytochrome $\mathrm{P} 450$, is induced by retinoic acid and defines a new family. J Biol Chem 272:18702-18708.

REIJNTJES, S., GALE, E. and MADEN, M. (2003). Expression of the retinoic acid catabolising enzyme CYP26B1 in the chick embryo and its regulation by retinoic acid. Gene Expr Patterns 3: 621-627.

REIJNTJES, S., BLENTIC, A., GALE, E. and MADEN, M. (2005). The control of morphogen signalling: Regulation of the synthesis and catabolism of retinoic acid in the developing embryo. Dev Biol 285: 224-237.

REIJNTJES, S., STRICKER, S. and MANKOO, B.S. (2007a). A comparative analysis of Meox1 and Meox2 in the developing somites and limbs of the chick embryo. Int J Dev Biol 51: 753-759.

REIJNTJES, S., RODAWAY, A. and MADEN, M. (2007b). The retinoic acid metabolising gene, CYP26B1, patterns the cartilaginous cranial neural crest in zebrafish. Int J Dev Biol 51: 351-360

ROBSON, L.G., KARA, T., CRAWLEY, A. and TICKLE, C. (1994). Tissue and cellular patterning of the musculature in chick wings. Development 120: 12651276.

RODRIGUEZ-GUZMAN, M., MONTERO, J.A., SANTESTEBAN, E., GAÒAN, Y MACIAS, D. and HURLE, J.M. (2006). Tendon-muscle crosstalk controls muscle bellies morphogenesis, which is mediated by cell death and retinoic acid signalling. Dev Biol 302: 267-280.

SCHWEITZER, R., CHYUNG, J., MURTAUGH, L.C., BRENT, A.E., ROSEN, V., OLSON, E., LASSAR, A. and TABIN, C.J. (2001). Analysis of the tendon cell fate using Scleraxis, a specific marker for tendons and ligaments. Development 128: 3855-3866.

SOLURSH, M., DRAKE, C. and MEIER, S. (1987). The migration of myogenic cells from the somites at the wing level in avian embryos. Dev Biol 121: 389-396.

STANDEVEN, A.M., DAVIES, P.J.A., CHANDRARATNA, R.A.S., MADER, D.R., JOHNSON, A.T. and THOMAZY, V.A. (1996). Retinoid-induced epiphyseal closure in guinea pigs. Fundam Appl Toxicol 34: 91-98.

SUNDIN, O. and EICHELE, G. (1992). An early marker of axial pattern in the chick embryo and its respecification by retinoic acid. Development 114: 841-852.

SWINDELL, E.C., THALLER, C., SOCKANATHAN, S., PETKOVICH, M., JESSELL, T.M. and EICHELE, G. (1999). Complementary domains of retinoic acid production and degradation in the early chick embryo. Dev Biol 216: 282-296.

TANAKA, M., TAMURA, K. and IDE, H. (1996). Citral, an inhibitor of retinoic acid synthesis, modifies chick limb development. Dev Biol 175: 239-47.
THALLER, C. and EICHELE, G. (1987). Identification and spatial distribution of retinoids in the developing chick limb bud. Nature 327: 625-628.

TICKLE, C., ALBERTS, B., WOLPERT, L. and LEE, J. (1982). Local application of retinoic acid to the limb bud mimics the action of the polarizing region. Nature 296: 564-566.

VASYUTINA, E., STEBLER, J., BRAND-SABERI, B., SCHUIZ, S., RAZ, E. and BIRCHMEIER, C. (2005). CXCR4 and Gab1 cooperate to control the development of migrating muscle progenitor cells. Genes Dev 19: 2187-98.

WHITE, J.A., GUO, Y.D., BAETZ, K., BECKETT-JONES, B., BONASORO, J., HSU, K.E., DILWORTH, F.J., GONES, G. and PETKOVICH, M. (1996). Identification of the retinoic acid-inducible all-trans-retinoic acid 4-hydroxylase. J Biol Chem 271: 29922-29927.

WHITE, J.A., BECKETT-JONES, B., GUO, Y.D., DILWORTH, F.J., BONASORO, J., JONES, G. and PETKOVICH, M. (1997). cDNA cloning of human retinoic acid-metabolizing enzyme (hP450RAl) identifies a novel family cytochromes P450. J Biol Chem 272: 18538-18541.

WHITE, J.A., RAMSHAW, H., TAIMI, M., STANGLE, W., ZHANG, A., EVERINGHAM S., CREIGHTON, S., TAM, S.P., JONES, G. and PETKOVICH, M. (2000) Identification of the human cytochrome P450, P450RAI-2, which is predominately expressed in the adult cerebellum and is responsible for all-trans-retinoic acid metabolism. Proc Natl Acad Sci USA 97: 6403-6408.

WHITE, J.C. HIGHLAND, M., KAISER, M. and CLAGETT-DAME, M. (2000). Vitamin $A$ deficiency results in the dose-dependent acquisition of anterior character and shortening of the caudal hindbrain of the rat embryo. Dev Bio 220: $263-284$

WILLIAMS, B.A. and ORDAHL, C.P. (1994). Pax3 expression in the segmental mesoderm marks the early stages in myogenic cell specification. Development 120: 785-796.

WILLIAMS, S.S., MEAR, J.P., LIANG, H., POTTER, S.S. ARONOW, B.J. and COLBERT, M.C. (2004). Large-scale reprogramming of neural crest gene expression by retinoic acid exposure. Physiol Genomics 19: 184-197.

WILSON, J.G., ROTH, C.B. and WARKANY, J. (1953). An analysis of the syndrome of malformations induced by maternal vitamin A deficiency. Effects of restoration of vitamin A at various times during gestation. Am J Anat 92: 189-217.

WILSON, L., GALE, E., CHAMBERS, D. and MADEN, M. (2004). Retinoic acid and the control of dorsoventral patterning in the avian spinal cord. Dev Biol269: 433446.

WOOD, H., PALL, G. and MORRISS-KAY, G. (1994). Exposure to retinoic acid before or after the onset of somitogenesis reveals separate effects on rhombomeric segmentation and HoxB gene expression domains. Development 120: $2279-2285$

WOLBACH, S.B. (1947). Vitamin-A deficiency and excess in relation to skeleta growth. J Bone Joint Surg 29: 171-192.

XIAO, Y., GRIESHAMMER, U. and ROSENTHAL, N. (1995). Regulation of a muscle-specific transgene by retinoic acid. J Cell Biol 129: 1345-1354.

YANG, X.M., VOGAN, K., GROS, P. and PARK, M. (1996). Expression of the met receptor tyrosine kinase in muscle progenitor cells in somites and limbs is absent in Splotch mice. Development 122: 2163-2171.

ZAKERI, Z. and AHUJA, H.S. (1994). Apoptotic cell death in the limb and its relationship to pattern formation. Biochem Cell Biol 72: 603-613.

ZUCKER, R.M., HUNTER, S. and ROGERS, J. (1998). Confocal laser scanning microscopy of apoptosis in organogenesis stage mouse embryos. Cytometry 33: $348-354$

ZUCKER, R.M., HUNTER, S. and ROGERS, J. (1999). Practical confocal microscopy and the evaluation of system performance. Methods 18: 447-458. 


\section{Further Related Reading, published previously in the Int. J. Dev. Biol.}

See our recent Special Issue Fertilization, in honor of David L. Garbers and edited by Paul M. Wassarman and Victor D. Vacquier at: http://www.ijdb.ehu.es/web/contents.php?vol=52\&issue=5-6

\section{Comparative expression analysis of Pax3 and Pax7 during mouse myogenesis}

David Horst, Svetlana Ustanina, Consolato Sergi, Gregor Mikuz, Herbert Juergens, Thomas Braun and Eugene Vorobyov

Int. J. Dev. Biol. (2006) 50: 47-54

Changes in the proportion and number of Pax(7+ve) and MF20(+ve) myoblasts during chick myogenesis in the head and limb

Antonio S J Lee, Ming Zhang and Darrell J R Evans

Int. J. Dev. Biol. (2004) 48: 31-38

Myogenic potential of mouse primordial germ cells

Francesca-Gioia Klinger, Maria-Lucia Scaldaferri, Anna Di Carlo, Marta Baiocchi, Marcello Coletta, Giulio Cossu and Massimo De Felici

Int. J. Dev. Biol. (2003) 47: 303-305

\section{Limb muscle development}

Bodo Christ and Beate Brand-Saberi

Int. J. Dev. Biol. (2002) 46: 905-914

Determination, diversification and multipotency of mammalian myogenic cells G Cossu, L De Angelis, U Borello, B Berarducci, V Buffa, C Sonnino, M Coletta, E Vivarelli, M Bouche, L Lattanzi, D Tosoni, S Di Donna, L Berghella, G Salvatori, P Murphy,M G Cusella-De Angelis and M Molinaro Int. J. Dev. Biol. (2000) 44: 699-706

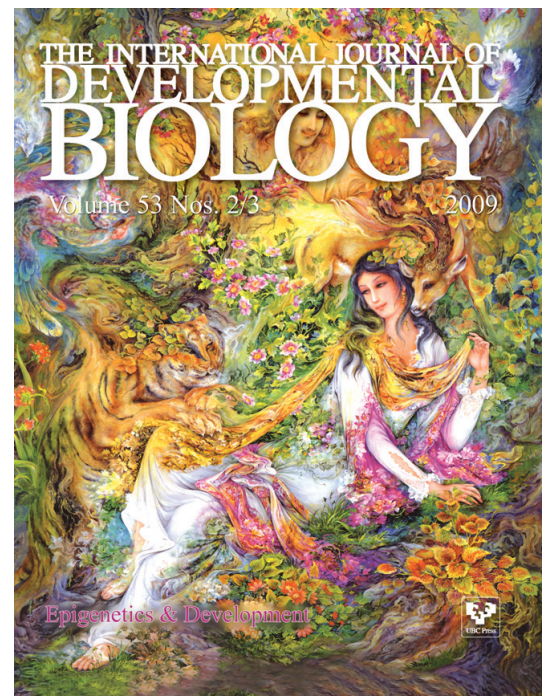

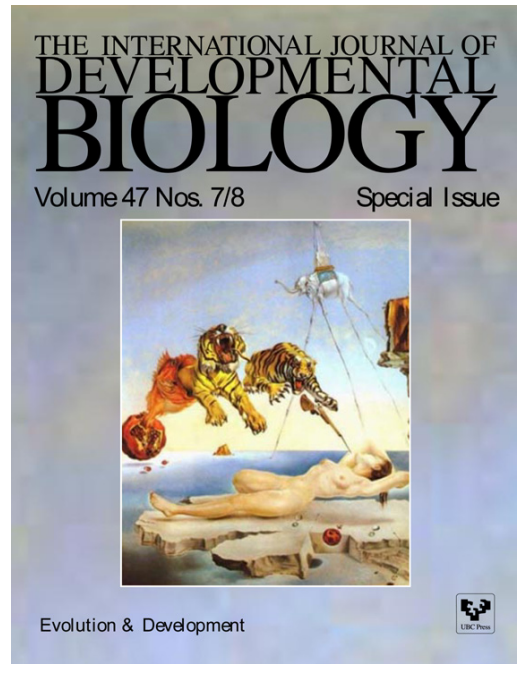

5 yr ISI Impact Factor $(2008)=3.271$

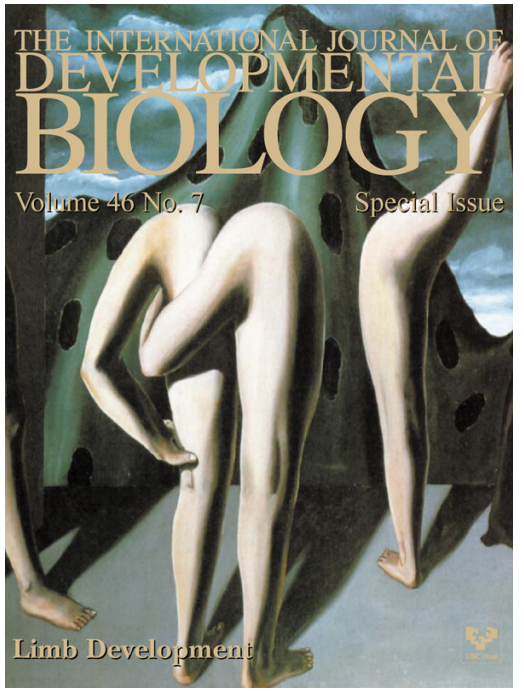

